\title{
Effects of constant and fluctuating temperatures on development and reproduction of Megoura crassicauda and Aphis craccivora (Hemiptera: Aphididae)
}

\author{
Li-Yuan Cheng, Yan Zhang, Zhen-Zhen Chen \& Yong-Yu Xu*
}

\begin{abstract}
Cheng, L.-Y., Zhang, Y., Chen, Z.-Z. \& Yong-Yu Xu, Y.-Y. 2018: Effects of constant and fluctuating temperatures on development and reproduction of Megoura crassicauda and Aphis craccivora (Hemiptera: Aphididae). — Entomol. Fennica 29: $1-12$.
\end{abstract}

The influence of fluctuating temperatures on the development and fecundity of two aphids, Megoura crassicauda Mordvilko and Aphis craccivora Koch, were determined by collecting life table data at a constant temperature $\left(22^{\circ} \mathrm{C}\right)$ and two fluctuating temperatures $\left(22 \pm 3{ }^{\circ} \mathrm{C}\right.$ and $\left.22 \pm 5^{\circ} \mathrm{C}\right)$. The longevity of $M$. crassicauda decreased significantly at $22 \pm 3{ }^{\circ} \mathrm{C}$ and $22 \pm 5^{\circ} \mathrm{C}$, while there was no significant difference in the longevity of $A$. craccivora among the three treatments. The fecundity and intrinsic rate of increase $(r)$ of $M$. crassicauda decreased significantly at both fluctuating temperatures, while $A$. craccivora showed the opposite tendency. These results showed that the fluctuating temperatures had negative impacts on the life history traits of $M$. crassicauda, but were beneficial for A. craccivora. Data obtained under constant temperatures may not reveal accurately enough the biotic responses of pests in the field.

L.-Y. Cheng, Y. Zhang, Z.-Z. Chen \& Y.-Y. Xu, Department of Entomology, The College of Plant Protection, Shandong Agricultural University, No. 61 Daizong Street, Tai'an, Shandong Province, 271018, China; *Corresponding author's email:xuyy@sdau.edu.cn

Received 2 December 2016, accepted 21 February 2017

\section{Introduction}

Biological control measures have been increasingly adopted worldwide as an alternative means of pest management. Knowledge of insect and mite adaptations to climatic conditions plays an essential role in biological control, specifically in helping to predict the emergence of pests and the scientific assessment and application of biological control agents (Hoelmer \& Kirk 2005). As ectothermic organisms, the development and fecundity of insects and mites are largely dependent on the temperature of their surrounding environ- ment (Trudgill et al. 2005). Many researchers conduct their studies under constant temperature conditions that have little, if any, variation. Consequently, their reports on various insect activities are based on observations made under unfluctuating temperature conditions. However, fluctuating temperatures are more relevant ecologically as compared to the temperatures that organisms actually experience daily and seasonally in the field (Lamb 1961, Hagstrum \& Hagstrum 1970) and in greenhouses (Tantau 1998, Pollet et al. 2009). In fact, many biological characteristics of insect and mite species, including body size 
(Beck 1983, Bahar et al. 2012), survival rate (Colinet et al. 2006 \& 2007, Carrington et al. 2013, Gotoh et al. 2014), developmental time (Niederegger et al. 2010, Chen et al. 2013), sex ratio (Vangansbeke et al. 2013), female fecundity (Hagstrum \& Leach 1973, Carrington et al. 2013), population growth rates (Mironidis \& Savopoulou-Soultani 2008, Vangansbeke et al. 2013) and immune function (Karl et al. 2011) can differ greatly when organisms are reared at fluctuating temperatures compared to constant temperatures. The mechanisms responsible for these developmental differences that occur at fluctuating versus constant temperatures are not completely known (Worner 1992, Liu et al. 1995, Vangansbeke et al. 2015).

Broad bean (Vicia faba L.) is an important legume crop and its planting area in China from 1961 to 2014 has generally been the widest in the world (FAOSTAT, 2017). Megoura crassicauda Mordvilko (=M. japonica Matsumura) and the cowpea aphid, Aphis craccivora Koch (Hemiptera: Aphididae), are key pests of broad bean, often causing serious damage (Singh \& Van Emden 1979, Zhou et al. 1996, Obopile \& Ositile 2010). Megoura crassicauda is an oligophagous aphid which feeds selectively on Vicia plants such as broad bean and narrowleaf vetch (Vicia angustifolia L.) (Fabaceae). Its body length of apterous adult can reach $3.7 \mathrm{~mm}$. Aphis craccivora is a worldwide key pest of leguminous crops and vegetables. It has a host range of 200 species of plants, leguminous and others, and can spread more than 50 plant viruses (Stoetzel \& Miller 2001). In biological control, the two aphids have been used as natural prey for year-round culturing of enemy insects under laboratory conditions (Gong et al. 2006, Chen et al. 2013). Understanding the effects of fluctuating temperatures on the survival, development and reproduction of $M$. crassicauda and A. craccivora are crucial for forecasting, managing and taking advantage of these two pests.

The life table is an important tool for determining biological characteristics and population growth of pests under certain environmental conditions (Bellows et al. 1992, Yu et al. 2013). In this study, we collected and compared life table data of $M$. crassicauda and A. craccivora under constant and fluctuating temperatures to deter- mine the influence of fluctuating temperatures on the biological parameters of these two aphid species.

\section{Materials and methods}

\subsection{Stock cultures}

Both $M$. crassicauda and A. craccivora were obtained from the Institute of Plant and Environmental Protection, Beijing Academy of Agriculture and Forestry Sciences, Beijing, China in 2009 and reared on broadbean (var. "Chongli") plants that were approximately $20 \mathrm{~d}$ old. The broadbean plants were grown in $12 \mathrm{~cm}$ diameter plastic pots using a soil mix (peat moss: perlite $=$ 3:1), and watered and fertilized as needed (Compost, COMPO Expert GmbH, Germany). The $M$. crassicauda, A. craccivora cultures, and broadbean plants were kept in a controlled-climate room at $22 \pm 1{ }^{\circ} \mathrm{C}, 60 \pm 5 \% \mathrm{RH}$ and the photoperiod of 15:9 (L: D) h.

\subsection{Experimental setup}

The meteorological data for the city of Tai' an during May of the years 2010 to 2015 were provided by the China Meteorological Administration (Fig. 1a). During those years, the average temperature in May was $21.6^{\circ} \mathrm{C}$ and the average maximum and minimum temperatures were $27.7^{\circ} \mathrm{C}$ and $15.6{ }^{\circ} \mathrm{C}$, respectively. Before starting our study, we considered several test conditions found in literature, and found that by Htwe et al. (2013) most similar with the daily meteorological data of Tai'an in May.

To simulate the effect of the above fluctuating field temperatures on the development and fecundity of $M$. crassicauda and A. craccivora, a constant temperature $\left(22^{\circ} \mathrm{C}\right)$ and two fluctuating temperatures $\left(22 \pm 3{ }^{\circ} \mathrm{C}\right.$ and $\left.22 \pm 5^{\circ} \mathrm{C}\right)$ were used in this study. The amplitudes of the fluctuating temperatures were $6{ }^{\circ} \mathrm{C}$ and $10^{\circ} \mathrm{C}$, respectively. The fluctuating temperatures were changed every $6 \mathrm{~h}$ from either the lower value (Tlow, $22^{\circ} \mathrm{C} \mathrm{mi-}$ nus half of the amplitude) or the upper value ( $T_{\text {up }}$, $22{ }^{\circ} \mathrm{C}$ plus half of the amplitude) to $22^{\circ} \mathrm{C}$, but, in doing so, the average daily temperature was maintained at $22{ }^{\circ} \mathrm{C}$ (Htwe et al. 2013). The temperature was increased or decreased at a rate of 


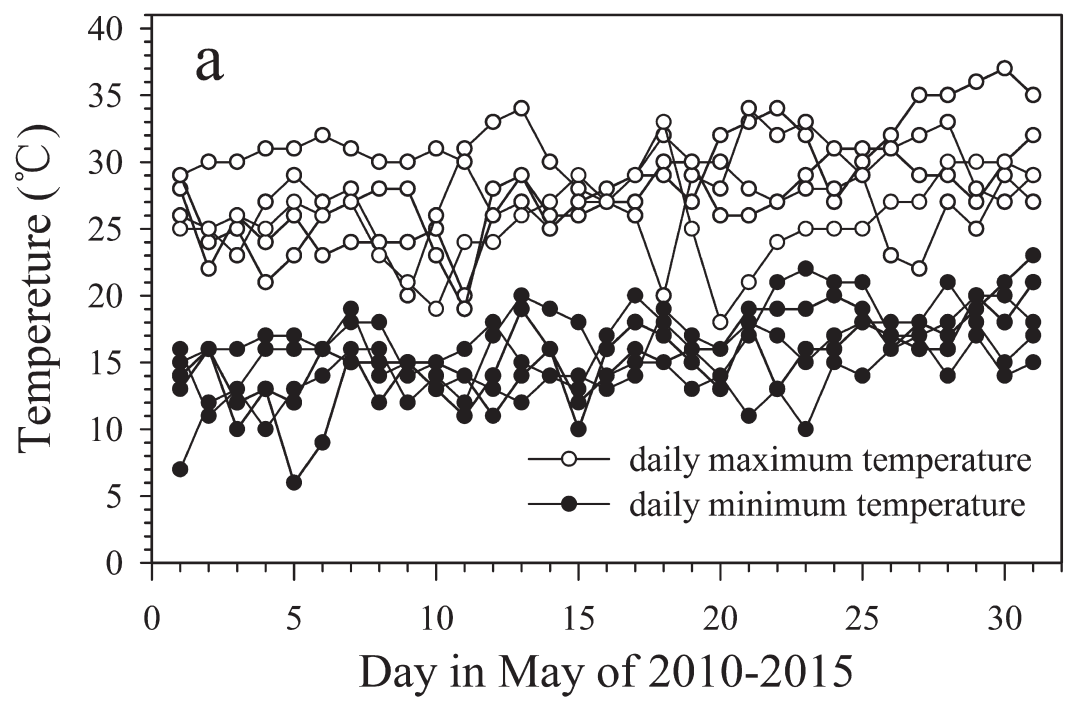

Fig. 1. - a. Highest and lowest temperatures in Tai'an area in May in 2010-2015. - b. Simulated fluctuating temperatures of temperature transition regimes during the experiments; photoperiodicity is also presented.

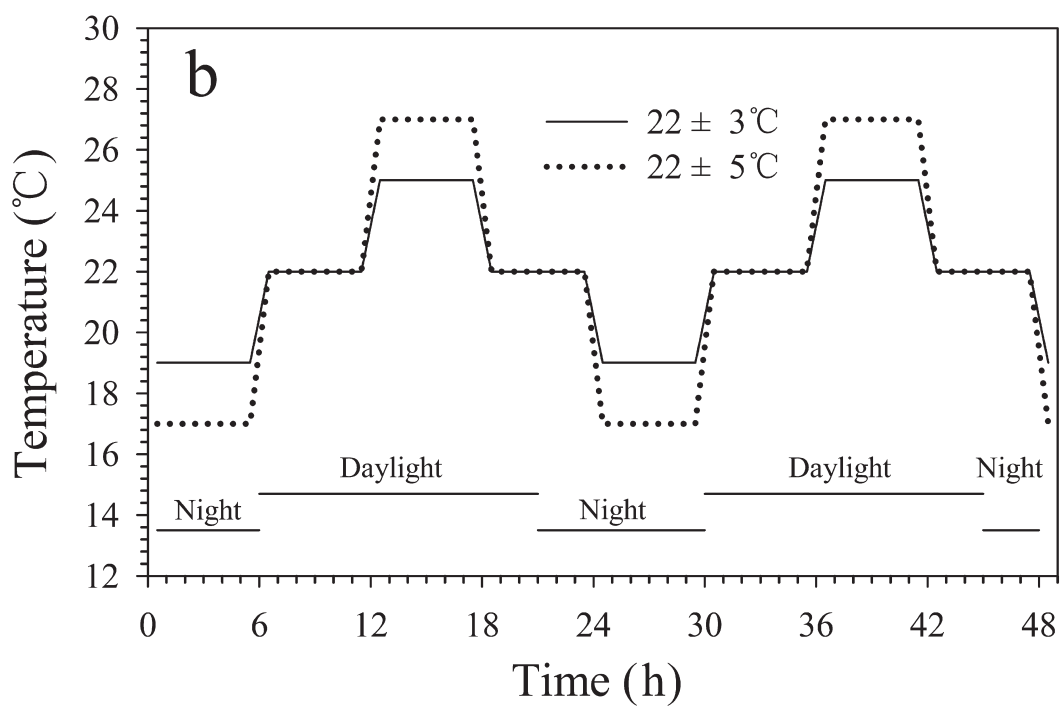

$0.5^{\circ} \mathrm{C} / \mathrm{min}$ and was completed in $10 \mathrm{~min}$. For example, the temperature regime in the $22 \pm 3{ }^{\circ} \mathrm{C}$ treatment was $19,22,25$ and $22^{\circ} \mathrm{C}$ during $00: 00$ 06:00, 06:00-12:00, 12:00-18:00 and 18:0024:00, respectively (Fig. 1b). The thermal error was $0.5^{\circ} \mathrm{C}$. The photoperiod was 15:9 (L: D) h, daylight hours were programmed for $06: 00$ 21:00. The relative humidity was $60 \pm 5 \%$ at each temperature regime.

\subsection{Life table study}

In a preliminary test, insects were reared at temperatures of $22^{\circ} \mathrm{C}, 22 \pm 3{ }^{\circ} \mathrm{C}$ and $22 \pm 5^{\circ} \mathrm{C}$ in con- trolled artificial climate chambers under the 15:9 (L:D) h photocycle (2,000 lux) and the $70 \pm 5 \%$ relative humidity. The life table experiments on $M$. crassicauda and A. craccivora were conducted by placing a 2-3 week old stem of the preflowering broadbean plant $(5 \mathrm{~cm}$ length) in each Petri dish ( $9.0 \mathrm{~cm}$ diameter, $3.0 \mathrm{~cm}$ height), along with a moistened cotton ball to keep the broadbean leaves and the stem fresh. The plants were replaced with fresh ones when necessary $(2-3 \mathrm{~d})$. Although we used stem segments, the above measures were adequate to keep them fresh for the relative short time of $2-3 \mathrm{~d}$. We do not either consider transferring the aphids from plant 
Table 1. Developmental time and fecundity (mean \pm SE) of Megoura crassicauda and Aphis craccivora at constant and fluctuating temperatures.

\begin{tabular}{|c|c|c|c|}
\hline Parameter & $22^{\circ} \mathrm{C}$ & $22 \pm 3^{\circ} \mathrm{C}$ & $22 \pm 5^{\circ} \mathrm{C}$ \\
\hline \multicolumn{4}{|l|}{ First instar (d) } \\
\hline M. crassicauda & $1.7 \pm 0.1 \mathrm{a}^{*}$ & $1.7 \pm 0.1 \mathrm{a}^{*}$ & $1.7 \pm 0.1 \mathrm{a}^{*}$ \\
\hline A. craccivora & $2.0 \pm 0.0 \mathrm{a}^{*}$ & $1.4 \pm 0.1 b^{*}$ & $1.4 \pm 0.1 b^{*}$ \\
\hline \multicolumn{4}{|l|}{ Second instar (d) } \\
\hline M. crassicauda & $1.6 \pm 0.1 \mathrm{a}^{*}$ & $1.4 \pm 0.1 b^{*}$ & $1.5 \pm 0.1 \mathrm{ab}$ \\
\hline A. craccivora & $1.1 \pm 0.1 b^{*}$ & $1.1 \pm 0.1 b^{*}$ & $1.4 \pm 0.1 \mathrm{a}$ \\
\hline \multicolumn{4}{|l|}{ Third instar (d) } \\
\hline M. crassicauda & $1.7 \pm 0.1 \mathrm{a}$ & $1.7 \pm 0.1 \mathrm{a}$ & $1.6 \pm 0.1 \mathrm{a}^{*}$ \\
\hline A. craccivora & $1.8 \pm 0.1 \mathrm{a}$ & $1.5 \pm 0.1 \mathrm{~b}$ & $1.3 \pm 0.1 b^{*}$ \\
\hline \multicolumn{4}{|l|}{ Fourth instar (d) } \\
\hline M. crassicauda & $2.0 \pm 0.0 \mathrm{a}^{*}$ & $2.1 \pm 0.1 a^{*}$ & $2.0 \pm 0.0 \mathrm{a}^{*}$ \\
\hline A. craccivora & $2.3 \pm 0.1 \mathrm{a}^{*}$ & $1.7 \pm 0.1 b^{*}$ & $1.7 \pm 0.1 b^{*}$ \\
\hline \multicolumn{4}{|l|}{ Preadult period $(\mathrm{d})$} \\
\hline M. crassicauda & $7.1 \pm 0.1 \mathrm{a}$ & $6.9 \pm 0.1 a^{*}$ & $6.8 \pm 0.1 b^{*}$ \\
\hline A. craccivora & $7.1 \pm 0.1 \mathrm{a}$ & $5.7 \pm 0.2 b^{*}$ & $5.8 \pm 0.1 b^{*}$ \\
\hline \multicolumn{4}{|l|}{ Adult period (d) } \\
\hline M. crassicauda & $21.4 \pm 1.0 a^{*}$ & $15.5 \pm 1.1 \mathrm{~b}$ & $11.0 \pm 0.8 c^{*}$ \\
\hline A. craccivora & $11.6 \pm 1.2 b^{*}$ & $14.0 \pm 1.2 \mathrm{~b}$ & $18.4 \pm 1.4 \mathrm{a}^{*}$ \\
\hline \multicolumn{4}{|l|}{ Longevity (d) } \\
\hline M. crassicauda & $28.4 \pm 0.9 a^{*}$ & $21.6 \pm 1.2 b$ & $17.6 \pm 0.8 c^{*}$ \\
\hline A. craccivora & $18.6 \pm 1.2 \mathrm{a}^{*}$ & $18.3 \pm 1.3 \mathrm{a}$ & $21.2 \pm 1.6 \mathrm{a}^{*}$ \\
\hline \multicolumn{4}{|l|}{ Oviposition period (d) } \\
\hline M. crassicauda & $16.4 \pm 0.6 a^{*}$ & $12.6 \pm 0.8 b$ & $9.3 \pm 0.7 c^{*}$ \\
\hline A. craccivora & $11.0 \pm 1.1 \mathrm{~b}^{*}$ & $12.4 \pm 1.0 \mathrm{~b}$ & $15.6 \pm 1.2 \mathrm{a}^{*}$ \\
\hline \multicolumn{4}{|c|}{ Fecundity (nymphs/female) } \\
\hline M. crassicauda & $86.8 \pm 3.4 a^{*}$ & $58.4 \pm 4.0 \mathrm{~b}$ & $44.6 \pm 3.7 c^{*}$ \\
\hline A. craccivora & $52.7 \pm 4.8 b^{*}$ & $66.4 \pm 5.0 \mathrm{a}$ & $73.3 \pm 5.6 a^{*}$ \\
\hline
\end{tabular}

Means for the same species in the same row followed by different letters are significantly different; Means for different species at the same temperature regime followed by an asterisk $\left(^{*}\right)$ are significantly different. Paired bootstrap tests, $P<0.05$.

segments to others every $2-3 \mathrm{~d}$ having been a notable cause of disturbance for the aphids. This is because $M$. crassicauda and $A$. craccivora are relatively active species and it was easy to transfer them after touching their antennas by a small brush. We did not use potted plants, because the nutrient levels of plants probably differ with their growing stage. For example, in a preliminary test, we found that aphids feeding on younger plants grew faster than those on older plants. In addition, stem segments occupy less space than potted plants, i.e. the former ones were more suitable for our artificial climate chambers.

A random apterous aphid female was placed on the bean plant stem of each petri dish and allowed to produce nymphs overnight. After $24 \mathrm{~h}$, the adult and all but one nymph were removed and the single remaining first instar nymph was allowed to develop on the broadbean stem. Each
Petri dish was checked daily and the development and reproduction of the individual was recorded until death. The sample size was $62,50,57$ individuals (petri dishes) for $M$. crassicauda population and 53, 50, 50 individuals for $A$. craccivora population in the $22{ }^{\circ} \mathrm{C}, 22 \pm 3{ }^{\circ} \mathrm{C}$ and $22 \pm 5^{\circ} \mathrm{C}$ treatment, respectively.

\subsection{Life table analysis}

The life history raw data of $M$. crassicauda and $A$. craccivora obtained at the constant and the two fluctuating temperatures were analyzed using the age-stage, two-sex life table theory developed by Chi and Liu (1985) and Chi (1988) to allow inclusion of the variable developmental rate that exists among individuals in a diverse population. We had only female aphids in our population. How- 


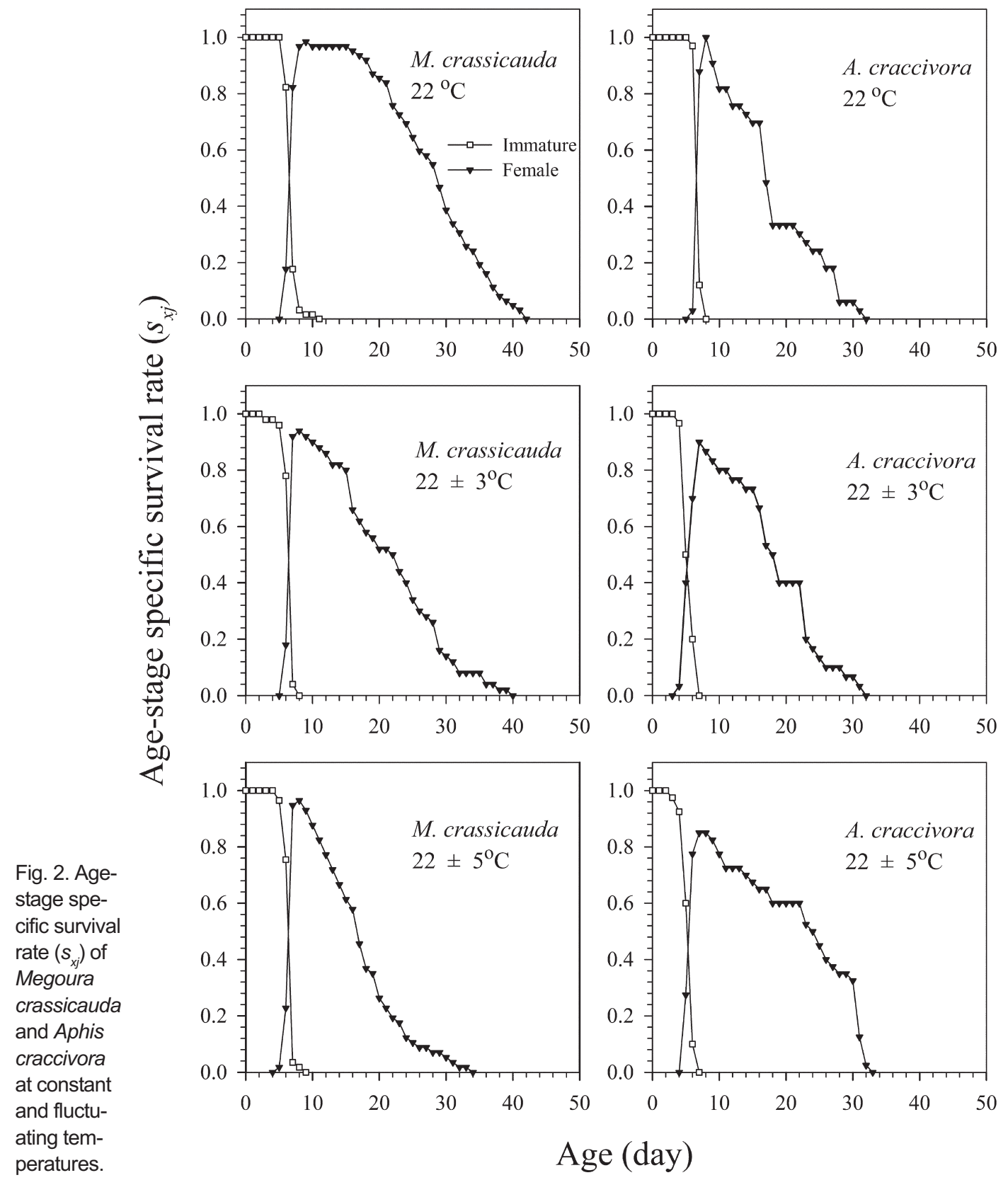

ever, the above approach allows missing males, i.e. it does not affect the results obtained for females. The age-stage, two-sex life table can (and should) also be applied for parthenogenetic populations, because contrary to the traditional female-based life table, it takes the pre-adult development and mortality into account and thus provides more accurate estimates of population parameters (Saska et al. 2016). The approach has been used also earlier for one-sex aphid studies by e.g. Akca et al. (2015), Akköprü et al. (2015) and Saska et al. (2016).

The developmental time, age-stage specific survival rate $\left(s_{x i}\right)$, age-specific survival rate $\left(l_{x}\right)$, age-stage specific fecundity $\left(f_{x j}\right)$, age-specific fecundity $\left(m_{x}\right)$, age-specific net fecundity $\left(1_{x} m_{x}\right)$, intrinsic rate of increase $(r)$, finite rate of increase $(\lambda)$, net reproductive rate $\left(R_{0}\right)$ and mean genera- 
tion time $(T)$ were calculated using the TWOSEX-MSChart program (Chi 2016a) as described by $\mathrm{Chi}$ and $\mathrm{Su}$ (2006), Tuan et al. (2014a, b) and Chi et al. (2016). The bootstrap technique (Efron \& Tibshirani 1993) with 100,000 resamplings was used to estimate the standard errors. The paired bootstrap test was used to compare differences between treatments. The growth of $M$. crassicauda and A. craccivora population at constant and fluctuating temperatures were projected based on the life table data using the program TIMING-MSChart (Chi 2016b) and the approach described in Tuan et al. $(2014 \mathrm{a}, \mathrm{b})$. The plots for survival rate, fecundity, life expectancy, reproductive value and the population growth curves were prepared using the program SigmaPlot 12.0.

\section{Results}

\subsection{Developmental time and fecundity}

The developmental times of different life stages as well as fecundity of females of $M$. crassicauda and $A$. craccivora were influenced by fluctuating temperatures (Table 1). The preadult period of $M$. crassicauda decreased gradually with the order of $22{ }^{\circ} \mathrm{C}, 22 \pm 3{ }^{\circ} \mathrm{C}$ and $22 \pm 5^{\circ} \mathrm{C}$, and a significant difference was found between $22^{\circ} \mathrm{C}$ and 22 $\pm 5{ }^{\circ} \mathrm{C}$. The adult period, longevity, oviposition period and fecundity of $M$. crassicauda decreased significantly with the order of $22^{\circ} \mathrm{C}, 22 \pm$ $3{ }^{\circ} \mathrm{C}$ and $22 \pm 5{ }^{\circ} \mathrm{C}$.

The preadult period of $A$. craccivora in $22^{\circ} \mathrm{C}$ treatment was significantly longer than those in the $22 \pm 3^{\circ} \mathrm{C}$ and $22 \pm 5^{\circ} \mathrm{C}$ treatments. The adult period, oviposition period and fecundity of $A$. craccivora increased with the order of $22^{\circ} \mathrm{C}, 22 \pm$ $3{ }^{\circ} \mathrm{C}$ and $22 \pm 5^{\circ} \mathrm{C}$, and the adult period and fecundity in the $22 \pm 5{ }^{\circ} \mathrm{C}$ treatment was significantly greater than those in two other treatments. The fecundity of $A$. craccivora in fluctuating temperature treatments was significantly greater than that in constant temperature treatment. There was no significant difference in the longevity among the three treatments.

The adult period, longevity and oviposition period were significantly longer and fecundity higher in M. crassicauda than in A. craccivora in the $22{ }^{\circ} \mathrm{C}$ treatment, while the opposite phenomenon was observed in the $22 \pm 5^{\circ} \mathrm{C}$ treatment.

\subsection{Age-stage survival rates}

The age-stage specific survival rates $\left(s_{x j}\right)$ of $M$. crassicauda and $A$. craccivora at different temperatures are plotted in Fig. 2. The age-stage specific survival rate was the probability of a newborn surviving to age $x$ and stage $j$. Because the age-stage, two-sex life table can take the variations in developmental rates that occur among individuals into consideration, significant overlapping between stages could be observed. The agespecific survival rate $(l)$, showing the survival rate to age $x$, is a simplified version of the agestage specific survival rate obtained by combining all stages (Fig. 3). These curves clearly showed that fluctuating temperatures had less influence on the preadult aphids, but had a great influence on the adult survival rate of both species. Megoura crassicauda adults had the longest longevity and highest survival rate at $22{ }^{\circ} \mathrm{C}$, followed by $22 \pm 3{ }^{\circ} \mathrm{C}$ and $22 \pm 5{ }^{\circ} \mathrm{C}$. On the contrary, the fluctuating temperatures, especially the $22 \pm 5^{\circ} \mathrm{C}$ treatment, increased the adult survival rate of $A$. craccivora.

\subsection{Fecundities}

The age-specific fecundity $\left(m_{x}\right)$ and the age-specific net fecundity $\left(l_{x} m_{x}\right)$ of $M$. crassicauda and $A$. craccivora are shown in Fig. 3. The age-specific fecundity $\left(m_{x}\right)$ curves of $M$. crassicauda and $A$. craccivora were characterized by a rapid increase to the maximum value at the beginning of the reproductive period and followed by a more gradual decrease with age in all three test temperatures. The curves showed that fluctuating temperatures, especially at $22 \pm 5{ }^{\circ} \mathrm{C}$, decreased the $m x$ value of $M$. crassicauda but increased that of $A$. craccivora. The age-specific fecundity curves of M. crassicauda peaked at the $9^{\text {th }}$ day, with maximum values of 7.0, 7.8 and 7.4 nymphs in the 22 ${ }^{\circ} \mathrm{C}, 22 \pm 3{ }^{\circ} \mathrm{C}$ and $22 \pm 5{ }^{\circ} \mathrm{C}$ treatments, respectively. The maximal $m_{x}$ value (11.4 nymphs) for A. craccivora occurred at $22{ }^{\circ} \mathrm{C}$ at age $8 \mathrm{~d}$. This value was significantly higher than those at $22 \pm 3$ 


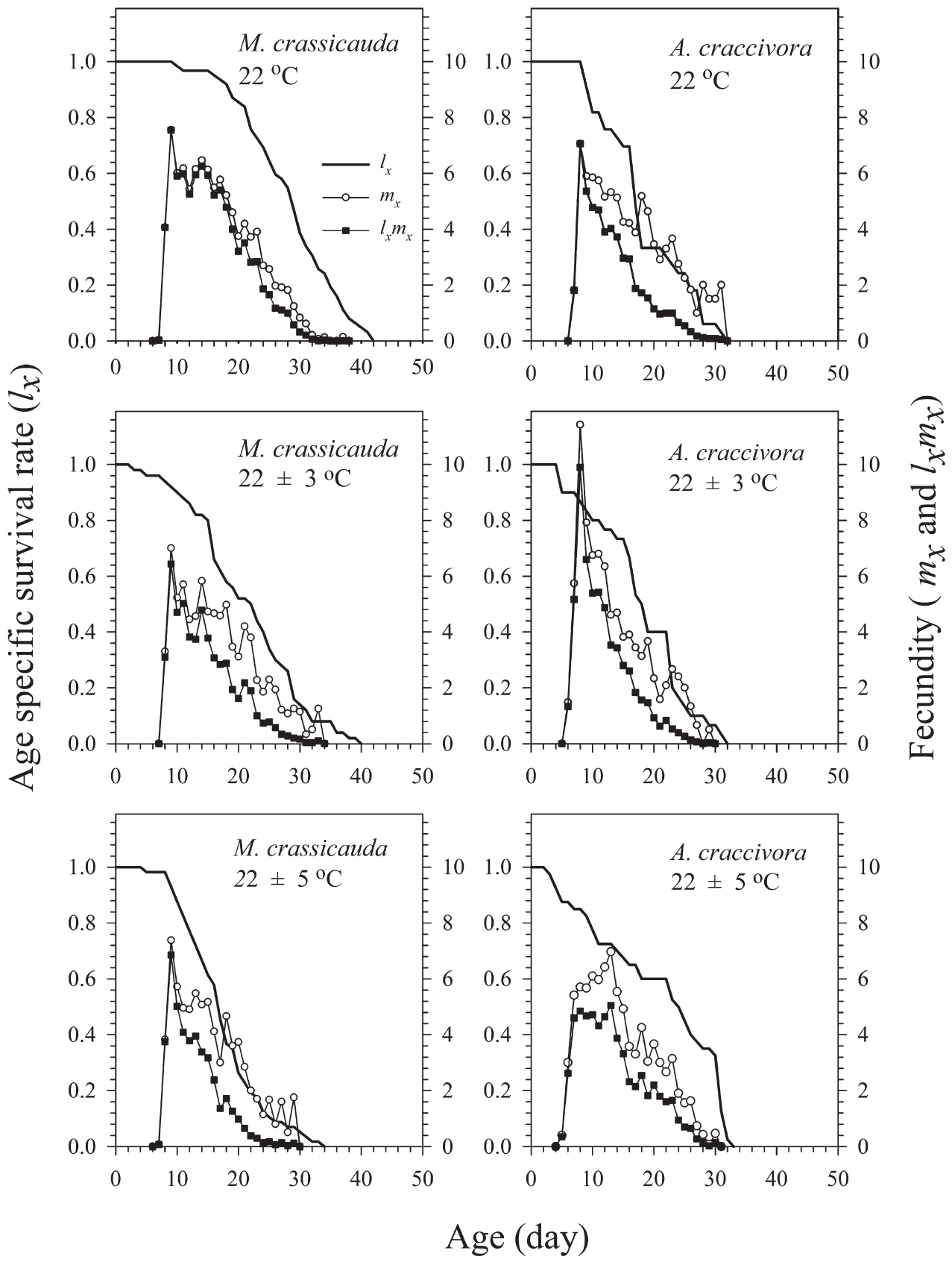

Fig. 3. Age-specific survival rate $\left(I_{x}\right)$, age-specific fecundity $\left(m_{x}\right)$, and age-specific net fecundity $\left(I_{x} m_{x}\right)$ of Megoura crassicauda and Aphis craccivora at constant and fluctuating temperatures.

${ }^{\circ} \mathrm{C}\left(7.1\right.$ nymphs at the $8^{\text {th }}$ day $)$ and $22 \pm 5^{\circ} \mathrm{C}(6.9$ nymphs at the $13^{\text {th }}$ day).

The age-specific net fecundity $\left(l_{x} m_{x}\right)$ values of $M$. crassicauda and A. craccivora under constant and fluctuating temperatures formed curves similar to the above age-specific fecundity. Compared with the constant temperature of $22{ }^{\circ} \mathrm{C}$, the $l_{x} m_{x}$ values of $M$. crassicauda decreased at the two fluctuating temperatures, whereas the values for A. craccivora increased. In general, oviposition ceased 2 to 6 days before death in both aphid species, except for $A$. craccivora at $22^{\circ} \mathrm{C}$. 
Table 2. Population parameters (mean \pm SE) of Megoura crassicauda and Aphis craccivora at constant and fluctuating temperatures.

\begin{tabular}{|c|c|c|c|}
\hline Parameter & $22^{\circ} \mathrm{C}$ & $22 \pm 3{ }^{\circ} \mathrm{C}$ & $22 \pm 5{ }^{\circ} \mathrm{C}$ \\
\hline \multicolumn{4}{|l|}{ Sample size $(n)$} \\
\hline M. crassicauda & 62 & 50 & 57 \\
\hline A. craccivora & 53 & 50 & 50 \\
\hline \multicolumn{4}{|c|}{ Intrinsic rate of increase $\left(r, \mathrm{~d}^{-1}\right)$} \\
\hline M. crassicauda & $0.3318 \pm 0.0039 a$ & $0.3093 \pm 0.0059 b^{*}$ & $0.3108 \pm 0.0061 b^{*}$ \\
\hline A. craccivora & $0.3360 \pm 0.0049 b$ & $0.3827 \pm 0.0096 a^{*}$ & $0.3691 \pm 0.0117 a^{*}$ \\
\hline \multicolumn{4}{|c|}{ Finite rate of increase $\left(\lambda, d^{-1}\right)$} \\
\hline M. crassicauda & $1.3935 \pm 0.0054 a$ & $1.3623 \pm 0.0080 b^{*}$ & $1.3646 \pm 0.0084 b^{*}$ \\
\hline A. craccivora & $1.3993 \pm 0.0069 b$ & $1.4663 \pm 0.0141 a^{*}$ & $1.4466 \pm 0.0168 a^{*}$ \\
\hline \multicolumn{4}{|c|}{ Net reproductive rate $\left(R, \mathrm{~d}^{-1}\right)$} \\
\hline M. crassicauda & $86.8 \pm 3.4 a^{*}$ & $56.1 \pm 4.1 \mathrm{~b}$ & $43.8 \pm 3.7 c^{*}$ \\
\hline A. craccivora & $52.7 \pm 4.8 a^{*}$ & $59.8 \pm 5.8 \mathrm{a}$ & $62.0 \pm 6.3 a^{*}$ \\
\hline \multicolumn{4}{|l|}{ Generation time $(T, \mathrm{~d})$} \\
\hline M. crassicauda & $13.5 \pm 0.1 a^{*}$ & $13.0 \pm 0.2 b^{*}$ & $12.2 \pm 0.2 c^{*}$ \\
\hline A. craccivora & $11.8 \pm 0.2 a^{*}$ & $10.7 \pm 0.1 b^{*}$ & $11.2 \pm 0.2 b^{*}$ \\
\hline
\end{tabular}

Means for the same species in the same row followed by different letters are significantly different; Means for different species at the same temperature regime followed by an asterisk $\left(^{*}\right)$ are significantly different. Paired bootstrap tests, $P<0.05$.

\subsection{Population parameters}

The population parameters of M. crassicauda and A. craccivora are listed in Table 2. Megoura crassicauda and $A$. craccivora had different responses to the temperature regimes. All population parameters of $M$. crassicauda were significantly higher in $22{ }^{\circ} \mathrm{C}$ treatment than in the $22 \pm 3$ ${ }^{\circ} \mathrm{C}$ and $22 \pm 5{ }^{\circ} \mathrm{C}$ treatments, but there were no significant differences in the intrinsic rate of increase $(r)$ and finite rate of increase $(\lambda)$ between $22 \pm 3{ }^{\circ} \mathrm{C}$ and $22 \pm 5{ }^{\circ} \mathrm{C}$.

The intrinsic rate of increase $(r)$ and finite rate of increase $(\lambda)$ of $A$. craccivora were higher in the $22 \pm 3{ }^{\circ} \mathrm{C}$ treatment than in the $22{ }^{\circ} \mathrm{C}$ and $22 \pm 5$ ${ }^{\circ} \mathrm{C}$ treatments, but they differed significantly only from those of the $22{ }^{\circ} \mathrm{C}$ treatment. The temperature regimes had no significant effect on the net reproductive rate $\left(R_{0}\right)$ of $A$. craccivora. The generation times $(T)$ of $A$. craccivora were significantly shorter in the $22 \pm 3{ }^{\circ} \mathrm{C}$ and $22 \pm 5^{\circ} \mathrm{C}$ treatments than in the $22^{\circ} \mathrm{C}$ treatment, but there was no significant difference between the $22 \pm 3{ }^{\circ} \mathrm{C}$ and the $22 \pm 5^{\circ} \mathrm{C}$ treatments. At constant $22^{\circ} \mathrm{C}$, intrinsic rate of increase $(r)$ and finite rate of increase $(\lambda)$ did not differ between the two aphid species, but $A$. craccivora population had significantly higher $r$ and $\lambda$ than M. crassicauda at the two fluctuating temperature regimes.

\subsection{Simulated population growth}

Population growths of $M$. crassicauda and $A$. craccivora, based on life table parameters, were affected by fluctuating temperatures (Fig. 4). According to the simulation, the population size after 50 days would differ by one order of magnitude and would reach approximately 48.21 million aphids at $22^{\circ} \mathrm{C}, 16.15$ million at $22 \pm 3{ }^{\circ} \mathrm{C}$, 18.29 million at $22 \pm 5^{\circ} \mathrm{C}$ for M. crassicauda and 68.60 million at $22{ }^{\circ} \mathrm{C}, 657.08$ million at $22 \pm 3$ ${ }^{\circ} \mathrm{C}, 360.60$ million at $22 \pm 5^{\circ} \mathrm{C}$ for A. craccivora . The simulated population growth curves (in a logarithmic scale) approached linearity after approximately 20 days, which suggests that the aphid populations had approached the stable agestage distribution. The slopes of the regression lines that describe such linear population increase are equal to $\log (\lambda)$ for each cohort (Table 2 ).

\section{Discussion}

The primary objective of this study was to understand the impact of fluctuating temperatures on the development and reproduction of $M$. crassicauda and A. craccivora. The effect were assessed by constructing age-stage, two-sex life tables at constant temperature of $22^{\circ} \mathrm{C}$ and simu- 
Fig. 4. Comparison of simulated population growth for Megoura crassicauda and Aphis craccivora at constant and fluctuating temperatures, based on agestage, two-sex life table. Regression equations describe linear population growth of each cohort from day 20 onwards as populations approached stable age-stage distribution.

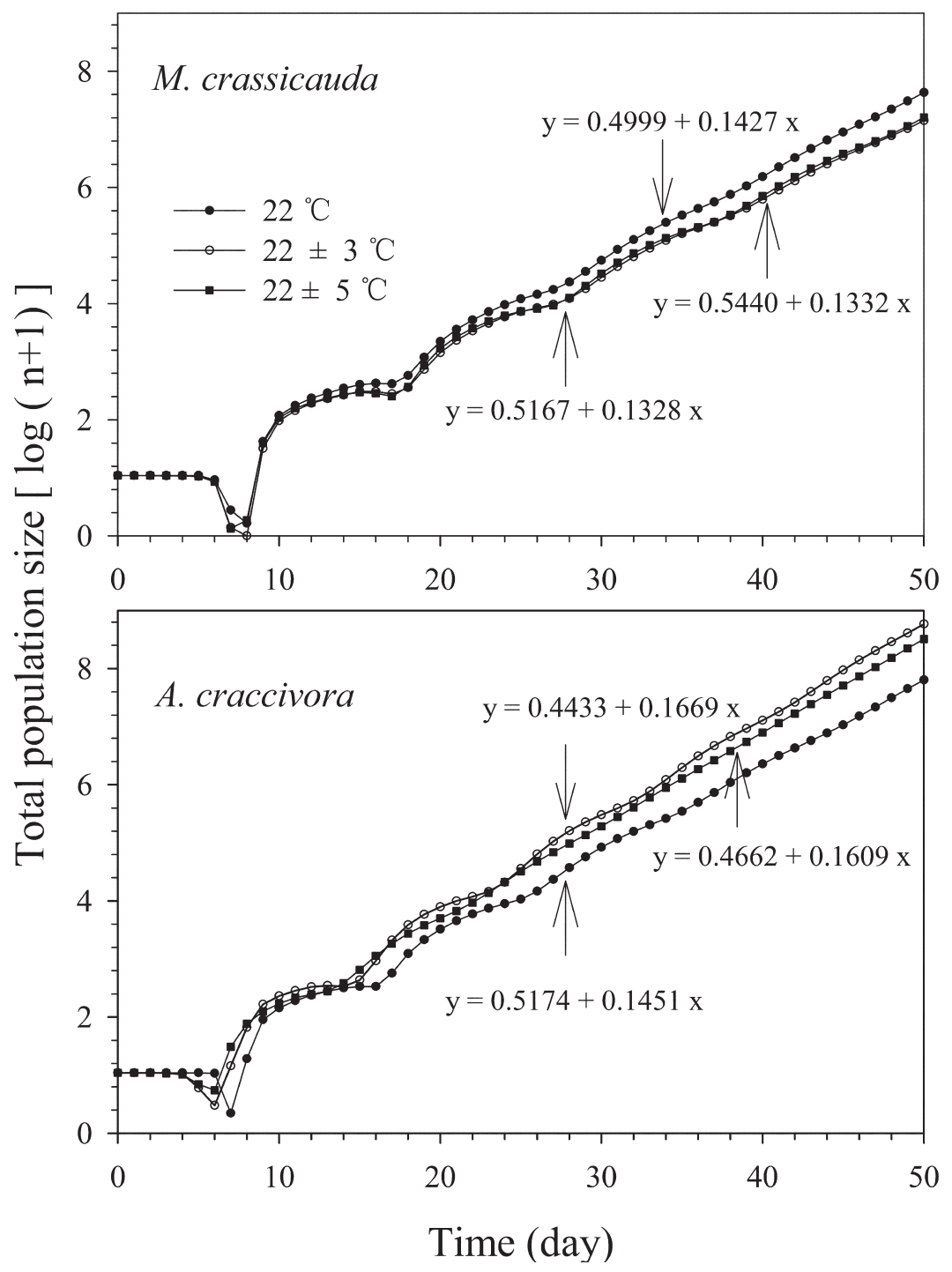

lated fluctuating temperatures of $22 \pm 3{ }^{\circ} \mathrm{C}$ and 22 $\pm 5^{\circ} \mathrm{C}$ with also a photoperiod to obtain a closer approximation of a natural field environment. Our results indicated that many life table parameters of $M$. crassicauda and A. craccivora at constant temperature did deviate from those at the two fluctuating temperatures, but the extent of the effects differed in the two aphid species.

In the present study, fluctuating temperatures accelerated the development of $M$. crassicauda and $A$. craccivora, as their preadult period was significantly shortened at fluctuating temperatures compared to the corresponding constant temperature. These findings are consistent with many of the earlier studies on a variety of arthropods (e.g., Brakefield \& Mazzotta 1995, Mironidis \& Savopoulou-Soultani 2008, Vangansbeke et al. 2013). For example, Bahar et al. (2012) reported that the developmental times of the diamondback moth, Plutella xylostella (Linnaeus), and its larval parasitoid Diadegma insulare (Cresson) were both shortened at fluctuating temperatures $\left(0-14,15-29\right.$ and $\left.23-37^{\circ} \mathrm{C}\right)$ compared to the same average corresponding constant temperatures $\left(7,22\right.$ and $\left.30^{\circ} \mathrm{C}\right)$. Generally, the relationship between poikilothermic developmental rates and temperature is nonlinear (Andrews \& Schwarzkopf 2012). Compared to the corre- 
sponding mean constant temperature, the developmental rate of poikilotherms tends to be higher at the low temperature range of fluctuating temperature regimes, lower in the higher temperature range, and little to no difference at intermediate temperatures (Vangansbeke et al. 2015). This effect has been referred to as the rate summation effect or Kaufmann effect (Ratte 1985, Worner 1992), explaining the differences between development predicted by nonlinear models under constant and variable temperatures with the same mean temperature.

Fluctuating temperatures $\left(22 \pm 3{ }^{\circ} \mathrm{C}\right.$ and $22 \pm$ $5^{\circ} \mathrm{C}$ ) reduced the adult survival rate of $M$. crassicauda, but that of $A$. craccivora was increased. Consequently, the oviposition period and fecundity of M. crassicauda decreased in both fluctuating temperature treatments, but increased for $A$. craccivora in the same treatments.

The intrinsic rate of increase $(r)$ combines the effects of several life table parameters, including the first reproductive age, the peak of reproduction, the length of the reproductive period, and the survival rate, on the population growth rate. These population parameters are key demographic parameters and are the most useful in predicting the growth potential of insect and mite populations (Birch 1948, Vangansbeke et al. 2013). Based on the $r$-values, the fluctuating temperatures in the present study had negative effect on the development and reproduction of $M$. crassicauda, but they were beneficial for $A$. craccivora.

Previous studies have demonstrated that the impact of fluctuating temperatures on insects and mites differed between species. Fluctuating temperatures can enhance the population growth rate of some insects, such as Helicoverpa armigera (Hübner) (Mironidis \& Savopoulou-Soultani 2008) and Tetranychus urticae Koch (Vangansbeke et al. 2013). On the other hand, some studies have reported an adverse effect of the fluctuating temperature (Siddiqui \& Barlow 1973), or no significant difference between two constant and fluctuating temperature treatments (Hagstrum \& Leach 1973). For aphid species, high temperatures can be harmful to developing embryos and thus have negative impacts on aphid populations (Harrison \& Barlow 1973, Nowierski et al. 1983). For instance, exposure to heat stress peri- ods (total of $16 \mathrm{~h}$ at $30^{\circ} \mathrm{C}$ ) significantly reduced the fecundity of Sitobion avenae (Fabricius) and resulted in a reduced population growth rate (Jeffs \& Leather 2014). For M. crassicauda and A. craccivora in the present study, there was no significant difference between the species in the population growth rate (intrinsic rate of increase) at the constant temperature, but the simulated $A$. craccivora population grew significantly faster than the $M$. crassicauda population in the two fluctuating temperature treatments. Thus, our present results may be due to that $A$. craccivora has more tolerance for high temperatures than $M$. crassicauda. A similar phenomenon was found at the constant temperatures, since $A$. craccivora could survive and reproduce at $31{ }^{\circ} \mathrm{C}$, while $M$. crassicauda cannot develop to adult at this temperature (Gong et al. 2006).

In conclusion, the fluctuating temperatures had negative impact on the life history traits of $M$. crassicauda, but was beneficial for A. craccivora. The data obtained under constant temperatures may not accurately reveal the biotic responses of pests in the field. Researchers should take these aspects into account when interpreting their laboratory data and making predictions about population growth in natural populations. In addition, information obtained from life table studies under daily fluctuating temperatures might be useful in mass production of biological control agents.

Acknowledgements. This work was supported by The Modern Tea Industry Technology System of Shandong Province, China (SDAIT-19-4), Post Research of Shandong Agricultural University, the Shandong Provincial Natural Science Foundation, China (ZR2014CP018), and The Technological System Project of Wheat Industry of Shandong Province, China (SDAIT-01-09). We thank Dr Hsin Chi for his valuable advice of the age-stage, two-sex life table concept.

\section{References}

Akca, I., Ayvaz, T., Yazici, E., Smith, C. L. \& Chi, H. 2015: Demography and population projection of Aphis fabae (Hemiptera: Aphididae): with additional comments on life table research criteria. - Journal of Economic Entomology 108(4): 1466-1478.

Akköprü, E. P., Atlihan, R., Okut, H. \& Chi, H. 2015: Demographic assessment of plant cultivar resistance to 
insect pests: a case study of the dusky-veined walnut aphid (Hemiptera: Callaphididae) on five walnut cultivars. - Journal of Economic Entomology 108(2): 378-387.

Andrews, R. M. \& Schwarzkopf, L. 2012: Thermal performance of squamate embryos with respect to climate, adult life history, and phylogeny. - Biological Journal of the Linnean Society 106(4): 851-864.

Bahar, M. H., Soroka, J. J. \& Dosdall, L. M. 2012: Constant versus fluctuating temperatures in the interactions between Plutella xylostella (Lepidoptera: Plutellidae) and its larval parasitoid Diadegma insulare (Hymenoptera: Ichneumonidae). — Environmental Entomology 41(6): 1653-1661.

Beck, S. 1983: Thermal and thermoperiodic effects on larval development and diapause in the European corn borer, Ostrinia nubilalis. - Journal of Insect Physiology 29(1): 107-112.

Bellows, T. S. Jr., Van Driesche, R. G. \& Elkinton, J. S. 1992: Life table construction and analysis in the evaluation of natural enemies. - Annual Review of Entomology 37(1): 587-612.

Birch, L. C. 1948: The intrinsic rate of natural increase of an insect population. - Journal of Animal Ecology 17: $15-26$.

Brakefield, P. M. \& Mazzotta, V. 1995: Matching field and laboratory environments: effects of neglecting daily temperature variation on insect reaction norms. Journal of Evolutionary Biology 8(5): 559-573.

Carrington, L. B., Seifert, S. N., Willits, N. H., Lambrechts, L. \& Scott, T. W. 2013: Large diurnal temperature fluctuations negatively influence Aedes aegypti (Diptera: Culicidae) life-history traits. - Journal of Medical Entomology 50(1): 43-51.

Chen, C. Y., Chiu, M. C. \& Kuo, M. H. 2013: Effect of warming with temperature oscillations on a low-latitude aphid, Aphis craccivora. - Bulletin of Entomological Research 103(4): 406-413.

Chi, B. J., Zheng, X., Liang, X. C. \& Liu, Y. 2016: Temperature-dependent demography of Agriphila aeneociliella (Lepidoptera: Crambidae), a new insect pest of wheat in China. - Agricultural and Forest Entomology 18(3): 189-197.

Chi, H. 1988: Life-table analysis incorporating both sexes and variable development rates among individuals. Environmental Entomology 17(1): 26-34.

Chi, H. 2016a: TWOSEX-MSChart: computer program for age stage, two-sex life table analysis. Available from: http://140.120.197.173/ecology/

Chi, H. 2016b: TIMING-MSChart: computer program for age stage, two-sex life table analysis. Available from: http://140.120.197.173/ecology/

Chi, H. \& Liu, H. 1985: Two new methods for the study of insect population ecology. - Bulletin of the Institute of Zoology 24(2): 225-240.

Chi, H. \& Su, H. Y. 2006: Age-stage, two-sex life tables of Aphidius gifuensis (Ashmead) (Hymenoptera: Braconidae) and its host Myzus persicae (Sulzer) (Homoptera: Aphididae) with mathematical proof of the relationship between female fecundity and the net repro- ductive rate. - Environmental Entomology 35(1): 10-21.

Colinet, H., Hance, T., Vernon, P., Bouchereau, A. \& Renault, D. 2007: Does fluctuating thermal regime trigger free amino acid production in the parasitic wasp Aphidius colemani (Hymenoptera: Aphidiinae)? Comparative biochemistry and physiology 147(2): 484-492.

Colinet, H., Renault, D., Hance, T. \& Vernon, P. 2006: The impact of fluctuating thermal regimes on the survival of a cold-exposed parasitic wasp, Aphidius colemani. — Physiological Entomology 31(3): 234-240.

Efron, B. \& Tibshirani, R. J. 1993: An introduction to the bootstrap. - Chapman and Hall, New York.

FAOSTAT, 2017: Food and agriculture data [www document]. URL http://www.fao.org/faostat/en/\#data/QC. (Site visited on 23 February, 2017)

Gong, Y. J., Shi, B. C., Lu, H., Zhang, S. L. \& Wei, L. 2006: Effects of temperatures on the development and fecundity of three species of aphids. - Acta Agriculturae Boreali-Sinica 21(5): 96-98. [In Chinese.]

Gotoh, T., Saito, M., Suzuki, A. \& Nachman, G. 2014: Effects of constant and variable temperatures on development and reproduction of the two-spotted spider mite Tetranychus urticae (Acari: Tetranychidae). Experimental \& Applied Acarology 64(4): 465-478.

Hagstrum, D. W. \& Hagstrum, W. R. 1970: A simple device for producing fluctuating temperatures, with an evaluation of the ecological significance of fluctuating temperatures. - Annals of the Entomological Society America 63(5): 1385-1389.

Hagstrum, D. W. \& Leach, C. E. 1973: Role of constant and fluctuating temperatures in determining development time and fecundity of three species of storedproducts Coleoptera. - Annals of the Entomological Society America 66(2): 407-410.

Harrison, J. R. \& Barlow, C. A. 1973: Survival of the pea aphid, Acyrthosiphon pisum (Homoptera: Aphididae), at extreme temperatures. - Canadian Entomologist 105(12): 1513-1518.

Hoelmer, K. A. \& Kirk, A. A. 2005: Selecting arthropod biological control agents against arthropod pests: Can the science be improved to decrease the risk of releasing ineffective agents? - Biological Control 34(3): 255-264.

Htwe, A. N., Murata, M., Takano, S. \& Nakamura, S. 2013: Effects of constant and fluctuating temperatures on development of the coconut hispine beetle, Brontispa longissima (Coleoptera: Chrysomelidae) and two species of parasitoid. - Biocontrol Science and Technology 23(5): 574-583.

Jeffs, C. T. \& Leather, S. R. 2014: Effects of extreme, fluctuating temperature events on life history traits of the grain aphid, Sitobion avenae. - Entomologia Experimentalis et Applicata 150(3): 240-249.

Karl, I., Stoks, R., De Block, M., Janowitz, S. A. \& Fischer, K. 2011: Temperature extremes and butterfly fitness: conflicting evidence from life history and immune function. - Global Change Biology 17(2): 676-687. 
Lamb, K. 1961: Some effects of fluctuating temperatures on metabolism, development, and rate of population growth in the cabbage aphid, Brevicoryne brassicae. — Ecology 42(4): 740-745.

Liu, S. S., Zhang, G. M. \& Zhu, J. 1995: Influence of temperature variations on rate of development in insects: analysis of case studies from entomological literature. - Annals of the Entomological Society America 88(2): 107-119.

Mironidis, G. K. \& Savopoulou-Soultani, M. 2008: Development, survivorship, and reproduction of Helicoverpa armigera (Lepidoptera: Noctuidae) under constant and alternating temperatures. - Environmental Entomology 37(1): 16-28.

Niederegger, S., Pastuschek, J. \& Mall, G. 2010: Preliminary studies of the influence of fluctuating temperatures on the development of various forensically relevant flies. - Forensic Science International 199(1): 72-78.

Nowierski, R. M., Gutierrez, A. P. \& Yaninek, J. S. 1983: Estimation of thermal thresholds and age-specific life table parameters for the walnut aphid (Homoptera: Aphididae) under field conditions. - Environmental Entomology, 12(3): 680-686.

Obopile, M. \& Ositile, B. 2010: Life table and population parameters of cowpea aphid, Aphis craccivora Koch (Homoptera: Aphididae) on five cowpea Vigna unguiculata (L. Walp.) varieties. - Journal of Pest Science 83(1): 9-14.

Pollet, B., Steppe, K., Dambre, P., Van Labeke, M. C. \& Lemeur, R. 2009: Temperature integration of Hedera helix L.: Quality aspects and growth response. - Scientia Horticulturae 120(1): 89-95.

Ratte, H. 1985: Temperature and insect development. In: Hoffmann, K. H. (ed.), Environmental physiology and biochemistry of insects: 33-66. Springer, New York. 296 pp.

Saska, P., Skuhrovec, J., Lukáš, J., Chi, H., Tuan, S.-J. \& Honěk, A. 2016: Treatment by glyphosate-based herbicide alters life history parameters of the rose-grain aphid Metopolophium dirhodum. - Scientific Reports 6, 27801. doi: 10.1038/srep27801.

Siddiqui, W. H. \& Barlow, C. A. 1973: Population growth of Anagasta kuehniella (Lepidoptera: Pyralidae) at constant and alternating temperatures. - Annals of the Entomological Society America 66(3): 579-585.

Singh, S. R. \& Van Emden, H. F. 1979: Insect pests of grain legumes. - Annual Review of Entomology 24(1): 255-278.

Stoetzel, M. B. \& Miller, G. L. 2001: Aerial feeding aphids of corn in the United States with reference to the rootfeeding Aphis maidiradicis (Homoptera: Aphididae). — Florida Entomologist 84: 83-98.

Tantau, H. J. 1998: Energy saving potential of greenhouse climate control. - Mathematics and Computers in Simulation 48(1): 93-101.

Trudgill, D. L., Honek, A., Li, D. \& van Straalen, N. M. 2005: Thermal time-concepts and utility. - Annals of Applied Biology 146(1): 1-14.

Tuan, S. J., Lee, C. C. \& Chi, H. 2014b: Population and damage projection of Spodoptera litura $(\mathrm{F}$.) on peanuts (Arachis hypogaea L.) under different conditions using the age-stage, two-sex life table. — Pest Management Science 70(5): 1936.

Tuan, S. J., Lee, C. C. \& Chi, H. 2014a: Population and damage projection of Spodoptera litura (F.) on peanuts (Arachis hypogaea L.) under different conditions using the age-stage, two-sex life table. - Pest Management Science 70(5): 805-813.

Vangansbeke, D., Audenaert, J., Nguyen, D. T., Verhoeven, R., Gobin, B., Tirry, L. \& De Clercq, P. 2015: Diurnal temperature variations affect development of a herbivorous arthropod pest and its predators. PLoS ONE 10(4): e0124898.

Vangansbeke, D., Schrijver, D. L., Spranghers, T., Audenaert, J., Verhoeven, R., Nguyen, D. T., Gobin, B., Tirry, L. \& De Clercq, P. 2013: Alternating temperatures affect life table parameters of Phytoseiulus persimilis, Neoseiulus californicus (Acari: Phytoseiidae) and their prey Tetranychus urticae (Acari: Tetranychidae). — Experimental \& Applied Acarology 61(3): 285298.

Worner, S. P. 1992: Performance of phenological models under variable temperature regimes: consequences of the Kaufmann or rate summation effect. - Environmental Entomology 21(4): 689-699.

Yu, J. Z., Chi, H. \& Chen, B. H. 2013: Comparison of the life tables and predation rates of Harmonia dimidiata (F.) (Coleoptera: Coccinellidae) fed on Aphis gossypii Glover (Hemiptera: Aphididae) at different temperatures. - Biological Control 64(1): 1-9.

Zhou, H., Li, Y. P., Shi, W. B. \& Liu, G. 1996: A study on the occurrence range trend prediction of broad bean aphids. - Southwest China Journal of Agricultural Sciences 9(2): 72-78. [In Chinese.] 